\title{
Research on the Supply Present Situation and the Structural Optimization Countermeasures of Public Sports Service in China
}

\author{
Shuying Wang, Lina Zhao \\ Hebei Normal University, College of Physical Education, Hebei, Shijiazhuang, China, 050024
}

Keywords: Public Sports, Service Supply, Status Quo, Structure, Optimization Strategy

\begin{abstract}
With the rapid development of social economy, Chinese urbanization and industrial construction process is accelerating, people's living standards and quality have been significantly improved, which have put forward higher requirements on the public services and infrastructure, which public sports service, with the enhance of health awareness of people, it promotes the development of public sports in China at a certain extent. This paper mainly analyzes and studies the current situation of the supply of public sports service and the effective measures to optimize the supply structure of public sports service in our country.
\end{abstract}

\section{Introduction}

Since the twentieth century, Chinese urbanization has gradually entered a critical period of rapid development, which improve people's living standards and quality of life at the same time, but also to change people's living habits, lifestyle, to a certain extent, greatly enriched Chinese public sports service products, and to promote the industry gradually to the supply of content diversification, supply diversification direction of the development of a good momentum. However, the actual situation, because the population in the city was explosive growth, which will further highlight and intensify the contradiction between supply and demand of public sports services, in particular, the original existence of historical problems, will seriously limit the development of urbanization process. On the level of public sports service supply, it is an important indicator of the level of development of sports in a country or region. Many scholars have gradually paid attention to the evaluation index of public sports service supply.

\section{The Current Status of Chinese Public Sports Service Supply}

In recent years, although the rapid development of the number of public sports service supply in China has significantly improved the quality of service, but through the analysis found that in many ways there are still serious problems, which is the most prominent of the supply and demand between the two contradiction.

\subsection{The Actual Area of Public Facilities Decreased While the Number of Facilities Increased}

The basic and prerequisite for the smooth development of the national public sports undertakings is good sports facilities. In recent years, China has added a lot of new sports facilities, such as the national construction base and fitness center, mass sports venues or sports parks. However, the actual coverage of the public sports facilities in the survey results show that the actual area of the downward trend, or even a maximum decline of $89 \%$, which will lead to public sports facilities, "virtual" phenomenon, in the development process Peripheral supporting area one-sided pursuit, and its own basic development characteristics have been ignored [1]. 


\subsection{The Proportion of Fiscal Expenditure Decreased While the Scale of Business Expenses to Expand}

In a national public sports service supply level measurement process, public sports undertakings are an important indicator. The results of related research show that the source of funding for sports in China is based on the financial input of the national sports. On the financial investment of sports, the financial investment in recent years has been increasing year by year. Especially in 2010, the growth rate can reach about $18 \%$, which can directly reflect the national government more and more attention to public sports undertakings; on the cost of sports expenses, but also showing a trend of increasing year by year in 2010, the average annual growth rate About $7 \%$ of its growth rate is relatively fast [2]. This shows that although China has increased the financial support of sports, but at present China has not yet formed a financial scale and public sports service expenditure costs between the natural growth mechanism, which also means that the public sports industry's own supply capacity is insufficient, but also natural Not to enhance, and thus cannot be very good to meet the needs of public services.

\subsection{Public Sports Organizations in the Urgent Need for the Development of Sports Organizations at the Same Time Government Institutions Bloated}

As a social group, management structure and public sports organization that specializes in mass sports related matters, it is the foundation and key to ensure the smooth development of public sports activities. Which is more developed countries, the public sports service supply is usually through a large number of social sports organizations to support and operate, in which the number of government agencies generally less, mainly because the role of government agencies for other organizations to carry out Public sports services provide policy guidance and financial support. At present, the actual situation of the development of public sports organizations in our country is that the number of government agencies is the majority, the level of mass sports organizations is relatively poor, and many are spontaneous people to carry out sports activities, cohesion is weak, loose high. Although in recent years, Chinese social sports organizations have shown a growth trend, but due to people's traditional ideas, national policy environment and other aspects of the impact of the whole society in a serious "political and social" phenomenon, in public sports services. It is difficult to supply the organizational function of social sports organizations, and the main body position is not highlighted, which will directly affect the quality of public sports service supply and supply efficiency [3].

\subsection{There Is a Large Contradiction between the Carrying Capacity of Public Sports Organizations and the Demand of Guidance Services}

The club is always carrying the public sports auxiliary guidance and gathering the popularity of the important social sports organizations, the current participation in the club to the number of activities and the club's own activities have been formed in the corresponding scale, the annual community sports club, community health club. The number of organizations related to training activities can generally reach about 10,000 times, and these two clubs is also an important form of social sports organizations. But through targeted analysis found that the number of annual training of these clubs were significantly decreased year by year trend, and the number of participants also decreased, the phenomenon is mainly due to public welfare social sports organizations in the lack of professional guidance [4].

\section{The Effective Countermeasures to Optimize Chinese Public Sports Service Supply Structure}

\subsection{Build an Integrated Public Sports Service Supply Model for the Purpose of Supply and Demand Balance}

On the current public sports service activities in China, are unified by the government arrangements, it is because of this supply of the main single, causing the needs of the broad masses 
of the people cannot be met, so in order to deal with the current public Sports service supply in the existence of various problems, it should be to achieve balance between supply and demand for the purpose of building an integrated public sports service supply model. First of all need to public sports services need to provide a wide range of content to the public to effectively comb, according to the specific nature of the product, broken down into the nature of the market of public sports service products, quasi-public sports service products, pure public sports service products type, which also means to strengthen the development of diversification, diversification of public sports service supply content is very necessary [5]. Secondly, it is necessary to actively construct the pattern of public sports service supply with the broad masses of the people as the main body, break the monopoly situation of the government and introduce the mechanism of social participation and market regulation, and comprehensively analyze the defects of the three development mechanisms and the corresponding measures to improve the efficiency and quality of public sports services, to achieve in the main body of public sports services, sports social organizations, the private sector, the public sector and other organizations to coordinate the development of their duties. Once again need to pay attention to the development of public sports service supply channels, which is to improve the public sports service supply model is reasonable, scientific and important means, according to the corresponding public sports services to have a different, differentiated arrangement of the corresponding path, and Actively introduce vouchers, subsidies, franchise, contract outsourcing, internal market, user payment, free supply and other different types of public sports services supply products. And finally to ensure that the masses of the public sports service needs can be well met. In view of the current phenomenon of public sports service demand in our country, that is, "uneven supply of all classes, the bottom of the supply shortage", but also according to Chinese urban construction process of the actual development of the situation, to build in line with Chinese actual situation, clear and clear, The public health service level supply system, but also need to focus on improving the supply of public sports service products, rationality, scientific and feasibility, to ensure that different classes of public sports service supply can achieve mutual promotion and common development [6].

\subsection{Improve People's Livelihood for the Purpose of Achieving the Basic Public Sports Service Supply Balance}

At present, China is in the critical period of social transformation and development. The demand of public sports service is also increasing. However, due to the problems in the development of public sports service supply, there is a certain imbalance between public sports service and people's demand. Which directly limits the sustainable development of Chinese public sports service supply. Therefore, it is necessary to design and implement a balanced public sports service development system, and to narrow the gap between urban and rural areas, the south and the north, the eastern and the western region as soon as possible, which is an important means to realize the balance of supply service of public sports service in China. On the one hand the need for the current public sports financial structure to effectively adjust to ensure that the regional financial expenditure in sports can reach $1 \%$, or even more. The establishment of the two natural docking mechanism, the use of policy tilt means, the various regions, the gap between the city and the countryside can be further reduced, while the national finance also need to improve the support of the West and other places, pay attention to normal development The effective construction of the path, in addition to the need to effectively release the central strategy of the rise of the relevant dividend, continue to invest in public sports finance special funds, and ultimately be able to further improve the pattern of collapse in the central region [7]. On the other hand, it is necessary to strengthen the improvement of the supply pattern of public sports facilities. All the development policies need to make the people's immediate needs as the reference standard, improve the basic, life and diversification of mass sports facilities, and also reasonable Planning space layout, will be convenient, small, multi-purpose public sports venues facilities, such as sports center, fitness path, sports venues and other facilities as a key development direction. In addition, it is necessary to break down the situation of mutual closure and segmentation, and fully activate the potential of public sports 
facilities. Will be the old commercial facilities, the old warehouse, the old plant space reasonable release, and strengthen the use of finance, policy, government purchase, transformation support and other methods of application, to achieve balanced development. Finally, it is necessary to give full play to the role of improving the supply of sports social organizations. The strong support and direct participation of sports social organizations in the development of public sports service supply is very important. Therefore, it is necessary to strengthen the support and cultivation of sports social organizations, the dominant position of the social organization is fully demonstrated.

\subsection{Improve the Stability of the Supply and Operation of Public Sports Services for the Purpose of Mechanism Innovation}

In order to promote the supply of public sports service smoothly and construct the operation route according to the specific supply design, we will construct a three-dimensional, multi-level and all-round operation guarantee mechanism to ensure the healthy, orderly, competitive and complementary development of public sports service supply. First, we will strengthen the construction of the multi-competitive mechanism of the supply of public sports services, break down the original "one dollar" monopoly system, narrow the scale and authority of the government supply departments, and actively introduce the public self-selection mechanism and service standardization management, and guide the public sector Better adapt to the demands [8]. The second is to strengthen the effective construction of the optimal decision-making mechanism, in the public sports services in the first demand and supply the best, unified public service supply grassroots democracy construction and decision-making process, truly make people decision-making, and people decision-making. Third, the establishment of a sound incentive and restraint mechanism, in order to ensure that the supply of public sports services can be comprehensive protection, the maximum activation of the supply of vitality in the implementation of the results and process throughout the constraints and incentives in the formation of public sports services in the formation of the pressure structure to achieve the best quality and effectiveness of supply. Fourth, to build the appropriate supervision and management mechanism, in the supervision and management into all the government, social organizations, the private sector and all public sports organizations, the formation of public sports service supervision together. At the same time, we can also apply the third party evaluation mechanism to effectively avoid the "rent-seeking" risk of the main body of public sports service [9]. In addition, we can establish a normal public sports project standardization, institutional evaluation and acceptance mechanism and the corresponding budget hearing system to ensure that public sports service supply can be scientific, reasonable and stable operation.

\section{Conclusion}

In order to further optimize the structure of public sports service supply in China, we need to build an integrated model of public sports service for the purpose of supply and demand balance, and make full use of the power of the broad masses of the people. Secondly, we need to improve the people's livelihood. The balance of public sports service supply to ensure that all the people of the country can enjoy the public sports services, which is also an important role in building a moderately prosperous society; Finally, the need for institutional innovation for the purpose of improving the stability of public sports service supply operation, Support the realization of public sports service sustainable development.

\section{Acknowledgements}

Fund Project: Hebei Province Sports Bureau Name: Hebei Province County Public Sports Service Supply Status and Equalization Research Number: 20142007 


\section{References}

[1] Hao Xiaochen. Investigation and Analysis on Public Service Supply of Mass Sports Government in Beijing[J]. Journal of Capital Institute of Physical Education, 2016,2804: 299-303.

[2] Qi Chao. Social organizations to participate in sports public service supply of the real dilemma and path selection - from Shanghai's enlightenment [J]. Tianjin Institute of Physical Education, 2016,3103: 252-258.

[3] Li Bing.Study on the Reform of Sports Public Service Supply Based on Good Governance Theory[J]. Journal of Nanjing Institute of Physical Education (Social Science Edition), 2016,3004: 54-60.

[4] Wang Wenqi, Jin Tao. From low level unbalanced to high level equilibrium - thinking on the change of development mode of public sports service in new countryside [J]. Journal of Wuhan Institute of Physical Education, 2014, 4809: 18-23.

[5] LIN Zheng-mei, WANG Jun-min, XU Wen-xin, DING Xiu-shi, CHEN Hua-wei, YAO Ji-wei.Characteristics and redefining the concept of urban community sports public service [J]. Journal of Capital Institute of Physical Education, 2014, 2605: 409-413.

[6] Huan Chang shop, Xiao Linpeng, Yang Xiping. County-level government supply of public sports services: responsibility, difficulties and breakthroughs [J]. Shandong Sports Technology, 2013, 3502: 1-5.

[7] Cui Jiujian.Study on optimization strategy of urban community public sports service supply [J]. Jiangsu Science and Technology Information, 2016, 36: 79-80.

[8] Zhao Fengxia, Zhang Xinhui, Zhang Yong. Xinjiang government sports public service supply capacity status and promotion path [J]. Sichuan Sports Science, 2017, 3602: 1-4 +20.

[9] Zheng Weimin, Ren Baoguo, Liu Dexin. The new era of urban community sports public service supply problem [J]. Physical Education and Science, 2012, 3301: 87-91. 